\title{
COVID-19 and acute kidney injury; a case report
}

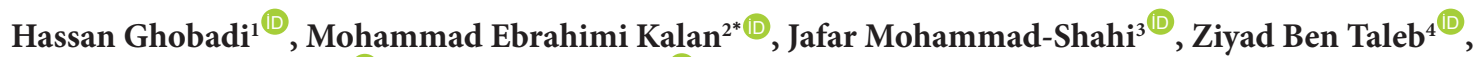 \\ Abbas Ebrahimi Kalan ${ }^{5}$, Mehdi Fazlzadeh ${ }^{6,7} \mathbb{0}$ \\ ${ }^{1}$ Department of Internal Medicine, Pulmonary Division, Faculty of Medicine, Ardabil University of Medical Sciences, Ardabil, Iran \\ ${ }^{2}$ Department of Epidemiology, Stempel College of Public Health, Florida International University, Miami, FL, USA \\ 3Department of Infectious Disease, School of Medicine, Ardabil University of Medical Sciences, Ardabil, Iran \\ ${ }^{4}$ Department of Kinesiology, College of Nursing and Health Innovation, University of Texas at Arlington, Arlington, TX, USA \\ ${ }^{5}$ Department of Neurosciences and Cognition, School of Advanced Medical Sciences, Tabriz University of Medical Sciences, Tabriz, Iran \\ ${ }^{6}$ Department of Environmental Health, School of Health, Ardabil University of Medical Sciences, Ardabil, Iran \\ ${ }^{7}$ Department of Environmental Health, School of Health, Tehran University of Medical Sciences, Tehran, Iran
}

\section{AR T I C L E I N F O}

Article Type:

Case Report

\section{Article History:}

Received: 9 May 2020

Accepted: 15 May 2020

Published online: 21 May 2020

\section{Keywords:}

COVID-19, Acute kidney injury,

Severe acute respiratory syndrome coronavirus 2

\begin{abstract}
A B S T R A C T
Although there is no definitive evidence that coronavirus disease 2019 (COVID-19) affects the kidneys adversely, amongst those who develop severe COVID-19 infection and require hospitalization, acute kidney injury (AKI) was reported. Here, we report the clinical outcome associated with AKI in a 32-year-old man with confirmed COVID-19 infection with no prior history of renal malfunction. The AKI was identified during intensive care unit (ICU) course with the median creatinine and blood urea nitrogen values of $3.1 \mathrm{mg} / \mathrm{dL}$ (normal value: 0.6-1.2 $\mathrm{mg} / \mathrm{dL}$ ) and $145 \mathrm{mg} / \mathrm{dL}$ (normal value:15-45 mg/dL), respectively. Renal function of patients hospitalized with COVID-19 infection needs to be monitored regularly to intervene as early as possible and to prevent the development of AKI and further kidney complications.
\end{abstract}

Implication for health policy/practice/research/medical education:

In the era of COVID-19 pandemic, renal function of the patients-with confirmed COVID-19 infection-needs to be regularly monitored during the hospitalization time to intervene as early as possible in order to curb the development of acute renal injuries (AKIs). Future epidemiological studies are warranted to determine the cause-effect relationship between COVID-19 and AKI. Please cite this paper as: Ghobadi H, Ebrahimi Kalan M, Mohammad-Shahi J, Ben Taleb Z, Ebrahimi Kalan A, Mehdi Fazlzadeh M, et al. COVID-19 and acute kidney injury; a case report. J Renal Inj Prev. 2020; 9(3): e26. doi: 10.34172/jrip.2020.26.

\section{Introduction}

Acute respiratory failure and diffuse alveolar damage are common clinical features of coronavirus disease 2019 (COVID-19) infection in hospitalized patients and can lead to multiple organ injuries. So far, there is no definitive evidence that COVID-19 infection affects the kidneys adversely. However, amongst those who develop severe infection and require hospitalization, acute kidney injury (AKI) was reported (1). We aim to present the clinical outcome associated with AKI in a case with confirmed COVID-19 infection.

\section{Case Presentation}

A 32-year-old man was admitted to Ardabil medical educational hospital in northwestern Iran on March 14th, 2020 with a 4 -day headache, myalgia, dry cough, shortness of breath, and fever $\sim 38^{\circ} \mathrm{C}$. He worked in a restaurant as a chef and reported that he had not traveled to a foreign country in the past 6-month but had contact with his co-worker who was coughing few days before the onset of his symptoms. The patient was admitted for suspected viral pneumonia in the emergency department. On admission day, transverse thoracic computed tomography (CT) scan showed patchy areas of ground-glass opacities with consolidation indicating the possibility of viral pneumonia (Figure 1). Appropriate antibiotics and hydroxychloroquine started on the admission day. Nasopharyngeal and oropharyngeal swabs were taken and tested positive for SARS-CoV-2 by real-time reversetranscription polymerase chain reaction (rRT-PCR) assay. None of the patient's family members developed COVID19-related symptoms, at the time of writing this report. 

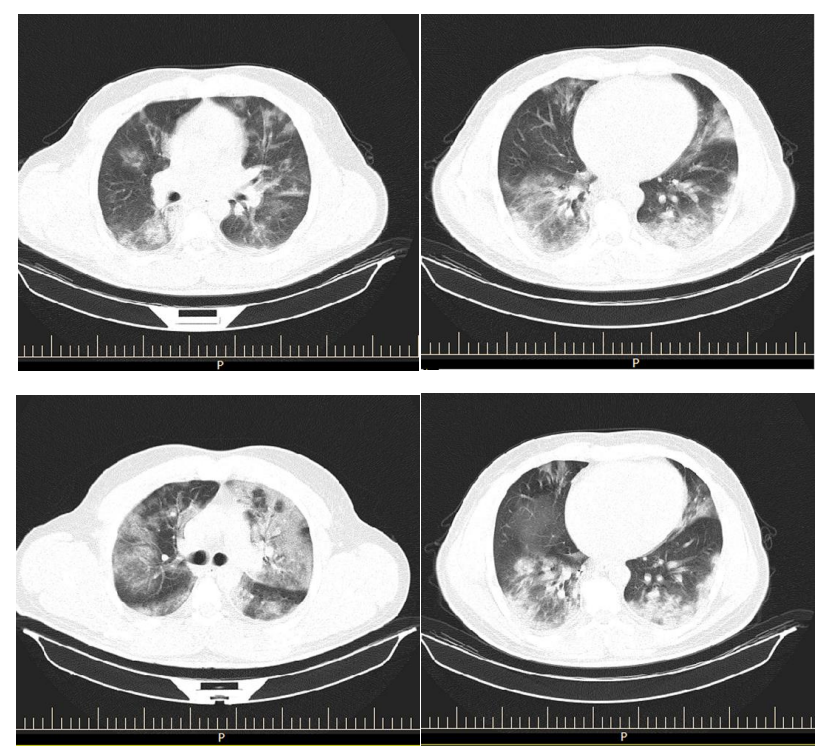

Figure 1. CT images of a 32-year-old patient with SARS-CoV-2. Note: Upper panel CT images were taken on day 1 (admission day) and bottom panels CT image were taken on day 7 of hospitalization. Left bottom panel show extensive ground glass opacities and occasional foci of consolidation.

On day 3, the patient was transferred to the intensive care unit (ICU) to receive ventilatory support. On day 7, the CT scan was repeated and showed multilobar bilateral lung consolidation with ground-glass opacities (Figure 1).

Table 1 shows the laboratory findings on admission day and during the ICU course. During the first three days of hospitalization, the patient reported no prior history of renal malfunction and his routine laboratory test results were within normal ranges. However, starting from day 4 , the values of some blood indicators were above the normal range including white blood cells, creatinine, urea, troponin, potassium and neutrophil/lymphocyte ratio. According to the kidney disease improving global outcomes classification (2), AKI is defined by an increase in serum creatinine over baseline $(2,3)$. For this patient, AKI was identified during ICU course with the median creatinine and blood urea nitrogen values as $3.1 \mathrm{mg} / \mathrm{dL}$ (normal value:0.6-1.2 $\mathrm{mg} / \mathrm{dL}$ ) and $145 \mathrm{mg} / \mathrm{dL}$ (normal value:15-45 $\mathrm{mg} / \mathrm{dL}$ ), respectively.

Once the patient transferred to the ICU, hydroxychloroquine was discontinued, and the patient was treated with the antiviral agent (i.e., Kaletra), meropenem, Targosid, and azithromycin for probable secondary bacterial lung infections. All the medications were adjusted with glomerular filtration rate during the ICU stay and the patient received appropriate intravenous fluid management. To manage respiratory failure, the patient was supported by mechanical ventilation using volume-controlled mode with low tidal volume strategy (6 cc/kg), high positive end-expiratory pressure level and maintain of plateau pressure below $30 \mathrm{~cm} \mathrm{H}_{2} \mathrm{O}$. Thrombosis prophylaxis with heparin and stress ulcer prophylaxis with pantoprazole was administered during the hospitalization. At the time of writing this report, the patient was transferred from ICU to the hospital ward.

\section{Discussion}

This report describes a critically ill patient who presented with laboratory-confirmed COVID-19 associated symptoms. The AKI for this patient was identified during the ICU course, which was consistent with previous studies showing AKI in hospitalized patients with confirmed COVID-19 (1) and contradicted another study that indicated COVID-19 infection does not result in AKI (4). Nevertheless, AKI was recognized as an independent risk factor for patients' in-hospital mortality due to COVID-19

Table 1. Laboratory Data at Hospital Admission and ICU course from day 1 to 16

\begin{tabular}{|c|c|c|c|c|c|c|c|c|c|c|c|c|c|c|}
\hline & Normal range & Day 1 & Day 4 & Day 6 & Day 7 & Day 8 & Day 9 & $\begin{array}{c}\text { Day } \\
10\end{array}$ & Day 11 & $\begin{array}{c}\text { Day } \\
12\end{array}$ & Day 13 & $\begin{array}{c}\text { Day } \\
14\end{array}$ & Day 15 & Day 16 \\
\hline Creatinine & $0.6-1.2 \mathrm{mg} / \mathrm{dL}$ & 1.1 & 2.0 & 4.0 & - & 4.0 & - & 3.4 & - & 3.1 & - & 2.7 & - & 2.8 \\
\hline Urea & $15-45 \mathrm{mg} / \mathrm{dL}$ & 35 & 63 & 61 & - & 169 & - & 148 & - & 145 & - & 161 & - & 129 \\
\hline $\mathrm{Na}$ & $132-145 \mathrm{mEq} / \mathrm{L}$ & 134 & 136 & 134 & - & 143 & - & 138 & - & 135 & - & 139 & - & 141 \\
\hline K & $3.5-5.0 \mathrm{mEq} / \mathrm{L}$ & 4.6 & 6 & 4.9 & - & 4.3 & - & 4.3 & - & 4.5 & - & 4.7 & - & 6.5 \\
\hline WBCs & $\begin{array}{l}4000-10000 / \\
\mathrm{mcL}\end{array}$ & 23200 & 31800 & - & 12800 & - & 15800 & - & 18400 & - & 16400 & - & 18700 & 13900 \\
\hline $\mathrm{Hb}$ & $13.5-17.5 \mathrm{~g} / \mathrm{dL}$ & 15.6 & 14.2 & - & 10.7 & - & 12.2 & - & 12.1 & - & 11.0 & - & 10.9 & 8.4 \\
\hline $\begin{array}{l}\text { Platelet } \\
\text { count }\end{array}$ & $\begin{array}{l}150000- \\
450000 / \mathrm{mcL}\end{array}$ & 301000 & 399000 & - & 287000 & - & 385000 & - & 462000 & - & 393000 & - & 380000 & 234000 \\
\hline $\begin{array}{l}\text { Lymphocyte } \\
\text { percent }\end{array}$ & $20-40$ percent & $7 \%$ & $6 \%$ & - & $5 \%$ & - & $4 \%$ & - & $7 \%$ & - & $10 \%$ & - & $12 \%$ & $11 \%$ \\
\hline $\begin{array}{l}\text { Lymphocyte } \\
\text { count }\end{array}$ & $\begin{array}{l}1000-4800 / \\
\mathrm{mc} / \mathrm{L}\end{array}$ & 1624 & 1908 & - & 640 & - & 632 & - & 1288 & - & 1640 & - & 2244 & 1529 \\
\hline Troponin & $<0.03$ & 2.2 & 0.18 & - & - & - & - & - & - & - & - & - & - & - \\
\hline
\end{tabular}

Abbreviations: $\mathrm{Na}$, sodium; $\mathrm{K}$, potassium; WBCs, white blood cells; Hb, hemoglobin. 
(5). Even minor acute variations in kidney function can result in short- and long-term dire consequences, including chronic kidney disease, end-stage renal disease, and decease $(3,6)$. Evidence shows that microvascular dysfunction, inflammation, and metabolic disorders are the main mechanisms of AKI $(2,7)$. Therefore, amidst the COVID-19 pandemic, which is already taking a toll on global health, early diagnosis and identification of the underlying etiology are essential to guide proper management. Appropriate infectious control, intravenous fluid management, and respiratory failure management can contribute to preventing further AKIs (2,7-9).

\section{Conclusion}

In sum, renal function of patients hospitalized with COVID-19 infection needs to be monitored regularly to intervene as early as possible and to prevent the development of AKI. Additional studies are warranted to determine the cause-effect relationship between COVID-19 and AKI.

\section{Acknowledgments}

We thank all hard-working doctors, nurses, and staff at Ardabil Medical Educational Hospital.

\section{Authors' contribution}

MEK and MF wrote the manuscript. HG and JMS were the physicians of the patient and completed data and helped in writing draft. HG and JMS treated and followed the patient and revisited the case. HG, MEK, ZBT, AEK reviewed the reported laboratory results. All authors were involved in the writing, review and editing of the manuscript and read and signed the final paper.

\section{Conflicts of interest}

The authors declared no conflicts of interest.

\section{Ethical considerations}

Ethical issues including plagiarism, double publication, and redundancy have been completely observed by the author. The subject provided oral informed consent and gave the consent to publish as a case report. The
Institutional Review Board of the Ardabil University of Medical Science approved the study protocol.

\section{Funding/Support}

The authors declared no funding or support from any institution.

\section{References}

1. Naicker S, Yang C-W, Hwang S-J, Liu B-C, Chen J-H, Jha V. The Novel Coronavirus 2019 epidemic and kidneys. . Kidney Int. 2020;97:824-8. doi: 10.1016/j. kint.2020.03.001

2. Khwaja A. KDIGO clinical practice guidelines for acute kidney injury. Nephron Clin Pract. 2012;120:c179-84.

3. Lameire NH, Bagga A, Cruz D, De Maeseneer J, Endre Z, Kellum JA, et al. Acute kidney injury: an increasing global concern. The Lancet. 2013;382(9887):170-9.

4. Wang L, Li X, Chen H, Yan S, Li D, Li Y, et al. Coronavirus disease 19 infection does not result in acute kidney injury: an analysis of 116 hospitalized patients from Wuhan, China. Am J Nephrol. 2020:16.

5. Cheng Y, Luo R, Wang K, Zhang M, Wang Z, Dong $\mathrm{L}$, et al. Kidney disease is associated with in-hospital death of patients with COVID-19. Kidney Int. 2020. doi: 10.1016/j.kint.2020.03.005.

6. Fu D, Yang B, Xu J, Mao Z, Zhou C, Xue C. COVID-19 Infection in a Patient with End-Stage Kidney Disease. Nephron. 2020. doi: 10.1159/000507261

7. Peerapornratana S, Manrique-Caballero CL, Gómez $\mathrm{H}$, Kellum JA. Acute kidney injury from sepsis: current concepts, epidemiology, pathophysiology, prevention and treatment. Kidney Int. 2019;96(5):1083-99.

8. Valizadeh R, Baradaran A, Mirzazadeh A, Bhaskar LVKS. Coronavirus-nephropathy; renal involvement in COVID-19. J Renal Inj Prev. 2020;9(2):e18. doi: 10.34172/jrip.2020.18.

9. Aleebrahim-Dehkordi E, Reyhanian A, Saberianpour Sh, Hasanpour-Dehkordi A. Acute kidney injury in COVID-19; a review on current knowledge. J Nephropathol. 2020;9:e31. doi: 10.34172/jnp.2020.31.

Copyright (c) 2020 The Author(s); Published by Nickan Research Institute. This is an open-access article distributed under the terms of the Creative Commons Attribution License (http://creativecommons.org/licenses/by/4.0), which permits unrestricted use, distribution, and reproduction in any medium, provided the original work is properly cited. 